\title{
O Ensino de Línguas no Brasil de 1978. E Agora?
}

\author{
José Carlos Paes de Almeida Filho \\ UNICAMP
}

The year of 1978 saw the staging of the first academic event devoted to communicative language teaching in Brazil. The author traces his personal protagonism in communicative movement that is launched on that date. The article, then attempts to outline the still very recent history of the communicative ideas for language teaching in the country, reestablishing its foundations, potential and main obstacles for not deepening its roots and blossoming in the country's language teaching and applied research scenes.

\section{Introdução}

Vinte e três anos se passaram desde que me vi diante de uma platéia acadêmica em Florianópolis fazendo um balanço dos destroços do moderno estruturalismo audiolingualista no ensino de línguas fazendo a mesma pergunta contida no título deste trabalho: e agora para o ensino de línguas no Brasil? Naquele momento parecia correto e urgente para os que estavam no caminho da pesquisa e da reflexão sobre o ensino de línguas (EL) levantar essa indagação sobre o próximo estágio do desenvolvimento nacional nesse âmbito. Isso porque em 1978 voltávamos ao Brasil, depois de um programa de estudos pós-graduados em Lingüística Aplicada na Inglaterra, Carmen Rosa Caldas-Coulthard e eu. Ambos sentíamos o peso dos ventos de mudança que sopravam céleres na Europa do então Mercado Comum em construção nas questões educacionais e no âmbito do EL em particular para nós.

Aquele já longínquo Seminário sobre o ensino nocional-funcional, que se anunciava como doce promessa de renovação profissional, organizado por Carmen Rosa e colegas do curso de Letras da Universidade Federal de Santa Catarina, constituiu-se de fato na base pioneira de lançamento para o debate público e na primeira vitrine do que se anunciava como a nova maneira comunicativa de se planejar a operação de ensino de uma nova língua. 
Pareceu-nos à época que vivíamos a aurora da Era de Aquário para a Lingüística Aplicada e o Ensino de Línguas Estrangeiras (ELE).

$\mathrm{Na}$ Escócia e Inglaterra mais precisamente em Edimburgo e em Manchester, tínhamos atravessado o tufão filosófico das propostas comunicativas dos meados dos anos 70 e agora estávamos de volta a Florianópolis e São Paulo para enfrentar o sonho de mudança e atualização em terra pátria.

Do mesmo Seminário de Florianópolis constava como palestrante convidado o autor do que considerávamos como a primeira série didática funcional (baseada em funções comunicativas) a ser introduzida no Brasil - Brian Abbs, que juntamente como Ingrid Freebairn lançavam no país a então novidosa série Strategies. A série foi prontamente adotada nuns poucos centros mais atirados de ensino de inglês, entre eles, a PUC - São Paulo, a Sociedade Brasileira de Cultura Inglesa de São Paulo e a Universidade Federal de Santa Catarina.

A minha tese de mestrado sobre a abordagem nocional-funcional de um planejamento do curso para o contexto universitário brasileiro defendida no verão inglês de 1977 qualificava-me como palestrante (embora visivelmente inexperiente na tribuna da fala pública) e como debatedor da abordagem então emergente. Mais tarde essa abordagem (comunicativa) que se opunha à gramatical ou formalista seria reconhecida como um verdadeiro paradigma alternativo (para usar a nomenclatura de Kunh, 1970) para o ensino das línguas nas escolas. Esse paradigma ou modelo teórico, veríamos depois, não era um florão casual da Lingüística Aplicada mas um padrão novo alinhado com as profundas mudanças para as ciências iniciadas no último quartel do século $18 \mathrm{com}$ os trabalhos do filosófico alemão Hegel, conforme veremos ao final da seção 2 adiante.

No ano de 1976, quando me via mergulhado em pleno processo de compreender a dimensão nocional funcional da abordagem comunicativa, o lingüista aplicado David Wilkins ligado à Universidade de Reading, sul da Inglaterra, publicou com alarde nos meios acadêmicos o livro seminal Notional-Functional Syllabuses, nunca traduzido e provavelmente pouco lido no Brasil desde então. Desde 1972, época da implantação do então Mercado Comum Europeu (MCE), já havia artigos e documentos produzidos no bojo das comissões do MCE para os assuntos de aprendizagem das línguas da Comunidade. Havia artigos do próprio Wilkins, de membros de comissões encarregadas de traçar as novas 
diretrizes para o esforço europeu de renovação do ensino (Trim, Richterich, van Ek entre outros) e muitas idéias em gestação, como as de Henry Widdowson que em 78 publicaria também o livro seminal The Teaching of Language as Communication a partir do seu trabalho na Universidade de Edinburgo, na Escócia. Tendo sido aluno de Widdowson no programa de pós-graduação em Lingüística Aplicada de Edinburgo, Escócia, preparei eu mesmo a tradução dessa obra que em Português recebeu o título de $O$ Ensino de Línguas para a Comunicação.

Os ventos comunicativistas eram tão fortes que faziam lingüistas compenetrados em seu esforço descritivo do inglês redigirem versões comunicativistas da gramática (vide Leech e Svartvik, 1975 A Communicative Grammar of English). Críticas ao ensino audiolingualista então vigente já se acumulavam desde meados dos anos 60 (vide Newmark, 1966, por exemplo) tanto na Europa quanto nos Estados Unidos. O Brasil nessa época (décadas de 60 e 70) praticamente não tinha produção própria específica em teorização sobre o ensino de línguas e muito menos crítica sustentada do ensino estruturalista fortemente ortodoxo e em franca consolidação no país.

No início de 76 já corria nos meios acadêmicos britânicos a notícia da publicação próxima do livro de David Wilkins. Minha dissertação de mestrado já aprovada enquanto projeto não podia esperar que o livro chegasse a livraria da universidade e por isso viajei em junho a Reading em busca do texto tão aguardado. Em dois ou três dias turbulentos em Reading, mantive contato com colaboradores próximos de Wilkins (Keith Morrow e Keith Johnson) e voltei a Manchester com um exemplar do livro debaixo do braço.

Os conceitos que sustentavam o paradigma não eram claros para os neófitos e suspeito que também não o eram plenamente para os nossos professores nas universidades inglesas. Todos parecíamos, contudo, entusiasmados com a promessa renovadora contida na proposta comunicacional européia. Tínhamos já convicção (não evidências inequívocas) de que não estávamos lidando com mudanças apenas superficiais na ortodoxia metodológica estruturalista. Essa ortodoxia já vinha cansada a essa altura de uma campanha de desgaste conduzida por seus críticos e a ela se opunha agora a idéia do significado como a força organizadora central da aprendizagem começando pelo planejamento de cursos tão amplamente favorecido naquela época. As categorias de significados / conceitos se convertiam em nova metalinguagem para os 
planejadores e o procedimento de consulta aos alunos sobre seus interesses e necessidades deslocaram a gramática como preocupação central no processo de ensino e aprendizagem de uma nova língua. Essas características já nos faziam antever que algo importante e profundo estava ocorrendo enquanto fundamentação e prática do ensino de línguas.

Os professores em centros mais avançados de ensino de línguas no Brasil nessa época (por volta de 78) mostravam-se geralmente muito curiosos por conhecer e experimentar o ensino funcional mas alguns profissionais mais graduados à época apressaram-se em mostrar sua sobriedade cética solapando as infundadas esperanças de revolução. Uma crítica produzida em 1979 por Henry Widdowson, ele mesmo um proponente de idéias alinhadas com o movimento comunicativo, contra pressupostos da primeira geração de comunicativas funcionais, deu munição extra aos estruturalistas modernos brasileiros que se apressaram em dissipar altas expectativas (sem fundamento, segundo o autor) da revolução no ensino de línguas. $O$ movimento comunicativo seria um mero modismo fadado a uma trajetória efêmera sem maior impacto.

Após 23 anos da data da aprovação da minha dissertação em Manchester e do Seminário de Florianópolis é ainda válido indagar - e agora? É uma pergunta válida para um largo espectro do corpo profissional para que valeu-se desse período de tempo para familiarizar-se com as bases do comunicativismo. Quero dizer que ainda é lícito indagar "o que fazer do movimento comunicativo?". É ousadia fazer a pergunta, porque muitos já questionaram a vitalidade e validade dos fundamentos da filosofia comunicativa. Para alguns a abordagem teria fracassado na sua promessa de materializar a competência comunicativa nos aprendizes. Para outros haveria na abordagem problemas conceituais sérios (por exemplo, é ingênua na sua concepção de linguagem, no que projeta como papel do aprendiz, etc.) que a inviabilizariam afinal. Essa não é a minha posição conforme explicarei e argumentarei mais adiante no texto.

Tendo passado por muitas experiências de ensino de línguas (inglês e português como LE) ao longo dos anos, tendo trabalhado como trabalhei em tantos projetos de investigação direta de situações de ensino e aprendizagem e ofertado tantos cursos de formação de professores de línguas em minha carreira universitária, estou cada vez mais convencido de que o potencial comunicativo para o ensino de línguas é grande e continua inexplorado abaixo da superfície onde temos em geral atuado. Há muito a acrescentar e que transformar no paradigma emergente e no 
concreto da prática. A dimensão do que ainda é preciso formular pode intimidar numa primeira tomada de consciência mas devemos sempre reafirmar nossa disposição de avançar nos esforços de construção teórica e renovação cautelosa da prática nos anos e décadas vindouros.

Neste trabalho vou arriscar um condensado estado da arte da abordagem comunicativa do ensino de línguas tanto como paradigma para a formação de professores quanto para a pesquisa aplicada do processos vitais de ensino e aprendizagem de língua voltados para a aquisição. Ao enfrentar essas duas questões terei ocasião de recompor o paradigma comunicativo hoje sob ataques e enfrentando crises isoladas de desconfiança aqui e acolá além de tentar responder à questão que nos move nesta tarefa - e o que é que virá?

\section{Abordagem como filosofia de ensino e como paradigma de pesquisa}

Os professores de línguas precisam, entre outras cousas, produzir o seu ensino e buscar explicar porque procedem das maneiras como o fazem. Para dar conta desse duplo desafio, o movimento comunicativo tem sugerido alçarmos a posição mais alta o nível de abstração das crenças e pressupostos guias. Isso equivale a elevar a abstração do nível do método (materialidade de ensino, fórmula estável de ação pedagógica) para abordagem (conjunto de conceitos nucleados sobre aspectos cruciais do aprender e ensinar uma nova língua). Note-se que o alçamento dessa abstração se dá para um patamar ainda mais acima de metodologia tomada como conjunto de idéias que justificam o ensinar de uma certa maneira, isto é, um método. A abordagem é mais ampla e abstrata do que a metodologia por se endereçar não só ao método mas às outras três dimensões de materialidade do ensino, a saber, a do planejamento após a determinação dos objetivos, a dos materiais (que se escolhem ou se produzem) e a do controle do processo mediante avaliações.

A abordagem de ensinar é o resultado da plasmagem de um conjunto de concepções, sejam elas crenças implícitas ou pressupostos revelados à guisa de hipóteses em alguma configuração específica que a história de vida de cada professor se incumbe de gerar num campo de idéias onde forças outras atuam buscando se impor: idéias de ensinar de outros professores e agentes escolares (orientadores, coordenadores, diretores, 
pais de alunos) que têm poder nos contextos onde estiverem, as idéias de autores de materiais adotados e de formuladores de exames ou outros tipos de instrumentos de avaliação introduzidos no processo. Incide ainda como força concorrente à da abordagem do professor a concepção de aprender (a cultura de aprender conforme nomeei em outros trabalhos Almeida Filho, 1993, 1997, 1999) dos alunos aprendentes de línguas.

De forma sucinta, são 6 os formantes do construto da abordagem que se equacionam de algum modo em cada caso de ensino/aprendizagem:

- um conceito de aluno aprendente de língua como pessoa em processo de socialização humanizadora

- um conceito de língua estrangeira e de linguagem humana

- um conceito de aprender língua outra que não a LI

- um conceito de ensinar uma nova lingua a quem deseja ou precisa dela

- um conceito de sala de aula de lingua estrangeira (ou de representação do lugar de aprendê-la)

- um conceito de papéis a desempenhar no processo seja como aluno seja como professor

Uma dada abordagem exerce a força que tem através de uma combinação de competências (saberes e habilidades em várias composições), cada uma representada num nível específico de desenvolvimento em termos de funções que exercem, da implicitude ou explicitude dos elementos, da consciência e refinamento teórico com que podem operar. Assim, os professores agem a partir de um nível específico ou configuração de competências para obter qualidades variáveis na ação orientada pela equação da abordagem de ensino (obtida no confronto de forças históricas pessoais e outras forças externas em tensão). As competências previstas são as seguintes: competência implícita (que se desenvolve em nós a partir das experiências de aprender língua(s) que vivemos), competência teórica (corpo de conhecimentos que podemos enunciar), competência aplicada (o ensino que podemos realizar orientado e explicado pela competência teórica que temos), competência linguístico-comunicativa (a língua que se sabe e se pode usar) e a competência profissional (nosso reconhecimento do valor de ser professor de língua, nossa responsabilidade pelo avanço profissional próprio e dos outros e as ações correspondentes). 
Vejamos os formantes esboçados no diagrama apresentado na Fig.1 abaixo:

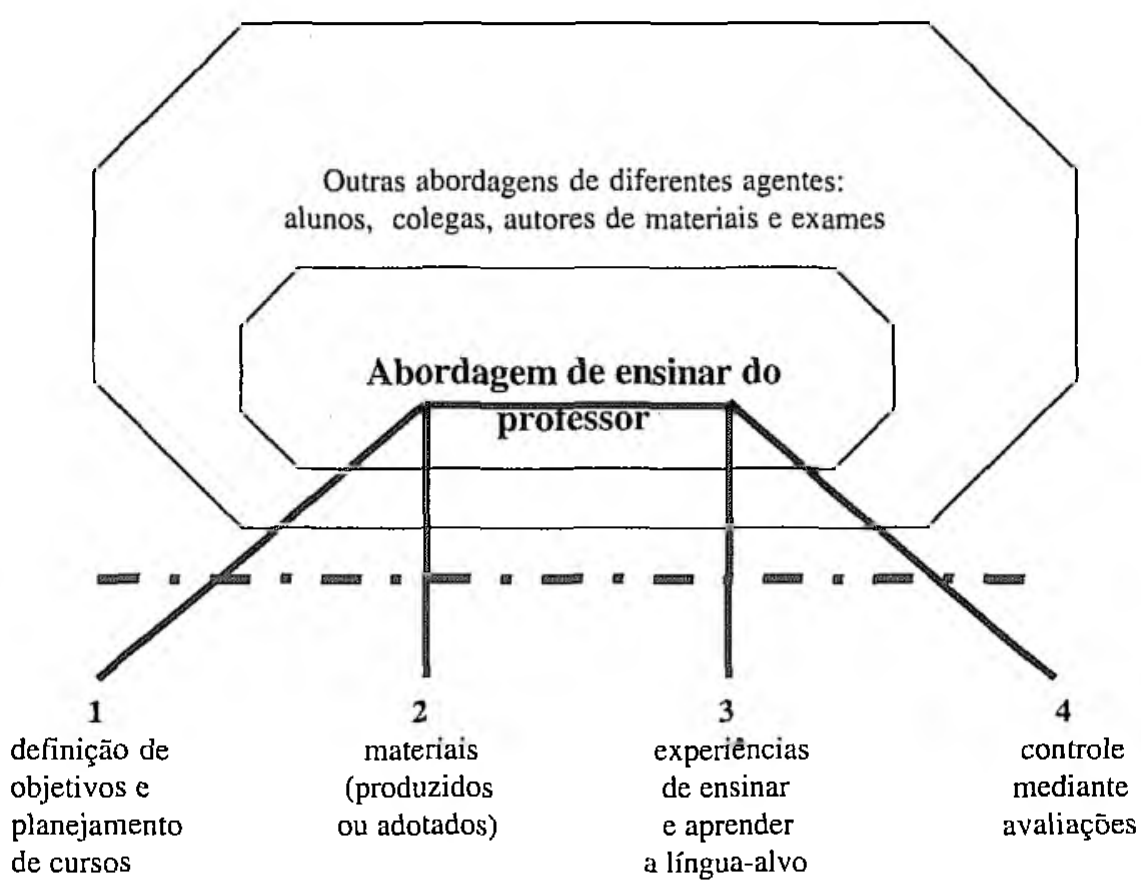

As definições mais precisas dos formantes ou elementos do construto da abordagem estão pormenorizadas em textos anteriores que podem ser acessados com facilidade. Vejam-se, por exemplo, Almeida Filho (1993, 1997 e 1999) e Barçante Alvarenga (1999) entre outros.

É suficiente lembrar aqui que muitas alterações nas condições e nas ações verificadas nas situações de ensino podem ocorrer para as quais não haverá alterações nos formantes conceituais. Nesse caso, diremos que ajustes superficiais nas materialidades do ensino-aprendizagem ocorreram e não mudanças propriamente ditas no âmbito mais alto e abstrato da abordagem que em última instância determina a natureza filosófica ou qualidade fundante do processo instaurado / vivido.

A abordagem foi tratada até aqui como filosofia ou concepções integradas de ensinar e aprender línguas para compreender e analisar o processo (interpretando aulas, avaliando materiais, investigando aprendizes em seus esforços de aprender, etc) e servir-se dele para formar 
novos professores ou auxiliar professores em busca de formação permanente/continuada. Mas poderíamos igualmente tomar a perspectiva da abordagem como refletidora de câmbios e equação contínua de um paradigma ou modelo de fazer pesquisa aplicada rumo à produção de mais conhecimentos relevantes sobre o ensino e aprendizagem de línguas nas condições que temos.

Nessa ótica de pesquisa, a abordagem radiografada e construída em construtos teóricos cada vez mais abrangentes e fundamentados serve como nucleadora de conceitos convergentes explicadores das ações típicas estudadas e das utopias da época colocadas no horizonte dos desejos profissionais dos professores. $\mathrm{O}$ alto poder de abstração permitido ao estudo da abordagem faculta a elevação do mesmo bem acima do patamar do método (como as experiências de ensinar e aprender a língua-alvo) e isso, por sua vez, permite-nos explicar porque a muitas mudanças ao nível do método não correspondem ganhos, ou alterações pelo menos, nos resultados da aprendizagem.

Na perspectiva da pesquisa em Lingüística Aplicada, a abordagem encapsula um corte epistêmico cujo reconhecimento rigoroso traz benefícios ao desenvolvimento teórico do ensino de línguas. A noção de paradigma que adoto aqui tem os sentidos apontados por Kuhn (1970): o de ser um caso exemplar, um exemplo tradicionalmente aceito a que um iniciante em ciência é exposto e que eventualmente vem a adotar ou uma matriz disciplinar composta de crenças comuns de uma comunidade de praticantes sobre como proceder num dado campo (o que vale como dados, boa metodologia, argumentos válidos, etc). Mas é no sentido de visão de mundo que creio existir o melhor potencial para explicarmos um paradigma de abordagem como a formal/gramatical ou a comunicativa/ sócio-interativa. Markova (1982) assinala a tensão nas ciências entre os paradigmas cartesiano e hegeliano que nos fazem refletir sobre os enfoques formal e comunicativo respectivamente. Vejamos o que relaciona a autora enquanto traços fundamentais dos dois macro-paradigmas para as ciências em geral: 
Arcabouço cartesiano

(Descartes, 1516-1650)

- natureza da mente é individual

- a mente é estática e passiva na aquisição do conhecimento

- conhecimento é adquirido através de logarítmos

- o critério do conhecimento é externo

- busca do que é certo (universais invariáveis)

- ahistórico
Arcabouço hegeliano

(Hegel, 1770-1831)

- natureza da mente é social

- mente é dinâmica e ativa na aquisição do conhecimento

- conhecimento é adquirido num círculo que retorna sempre a si mesmo

- o critério do conhecimento é interno

- natureza dialética do ser (só por contradição as coisas mudam

- histórico

\section{O ensino de línguas estrangeiras mo Brasil - o cenário da prática e o horizonte da vanguarda}

Há uma grande diferença no Brasil entre o que se prática de ensino de línguas nas escolas e salas de aula e o que projetam acadêmicos, teóricos e pesquisadores no cenário universitário dos cursos de Letras e programas de pós-graduação em Lingüística Aplicada, Letras e Estudos da Linguagem.

A cena cotidiana de ensino de línguas no país, além de díspar entre as regiões, é igualmente diversa quando consideramos o tipo de escola (se públicas, particulares, regulares ou instituto de línguas) e a realidade de alguns nichos (universitários experimentais, empresariais, imersivos temporários, etc).

A urgência de aprender uma nova língua para algum uso real pessoal e/ou profissional exacerba uma outra disparidade que nos acompanha há cinco séculos no Brasil: aprender para obter alguma distinção social no aprender mais sobre a língua-alvo do que o próprio novo idioma, e aprender para valer quando o aprendizado deve frutificar no trabalho, na formação, nos contatos interpessoais interpaíses. O aprender sobre pode se dar com o preceptor ou professor particular que a elite contrata ou com professores nos colégios e nas escolas popularizando o toque de distinção nos gestos de aprender para só quase ler (temos de lembrar que o quase falar foi rebaixado como objetivo nos Parâmetros Curriculares Nacionais). O aprender para desempenhar-se no domínio da nova língua foi por séculos no Brasil um filho da contingência e da urgência e por pouco mais de duas décadas antes do fim do século XX 
tornou-se uma idéia teórica para ser compreendida em sua anatomia e dinâmica nas salas de aula que não quisessem mais apenas o figurino da distinção.

É nisso que estamos. Nosso trem da distinção popularizada ainda corre veloz antes que possamos freiá-lo e mudá-lo de trilhos.

O cenário da prática que tem a estética da distinção (mesmo que pálida a ponto de quase nem ser reconhecível) é abalado por sinais de novos tempos (novas demandas em função de novas tecnologias e relações econômicas) e por condições depauperantes do tecido social onde ficam as escolas e do processo formativo dos novos professores.

O cenário alternativo da força no aprender em uso e para usos reais vai por um lado por novas exigências da vida e do trabalho e, por outro, pelo horizonte desejado por uma vanguarda ou elite acadêmica ocupada sistematicamente em reinventar caminhos.

Conforme já se pode ver, esta racionalização analítica de um agente acadêmico desqualifica a visão por movimentos cíclicos ou pendulares, ora estamos a ensinar forma explicitamente, ora só implicitamente. Sempre que essa imagem valer estaremos reforçando a noção de que nossa área é uma mera arena prática para eventuais aplicações de idéias momentosas do próprio Ensino de Línguas e das outras ciências, a lingüística principalmente entre elas.

Se não aceitarmos a imagem do pêndulo que vai e volta sem sair do lugar, sem que haja progresso, a pergunta "e agora?" poderia então querer dizer "o que mais agora?" ou "que novas transformações esperar agora?".

Se quiséssemos perguntar honestamente "o que é que devemos enfrentar agora como novos movimentos gerados pelas mudanças anunciadas?", a indagação seria de todo justa hoje em dia. Considerando-se que o movimento comunicativo faz vinte e três anos no Brasil em 2001, o primeiro no novo século, a questão que se põe não é exatamente sobre acréscimos ou variações do que se apresenta como o novo no ensino das línguas mas por um desejo no horizonte profissional que já lá está por algum tempo sem claras indicações de como compreendê-lo e como proceder informadamente para fruí-lo num esforço profissional nacional.

Se o ensino que estiver no horizonte do nosso desejo for de raiz vivencial do uso e não só um verniz de distinção despreocupada com o desempenho na nova língua, será preciso clarificá-lo e reafirmar seus traços distintivos centrais para dirimir confusões que praguejam os esforços de caminhar na direção do horizonte. 
Quando o ensino reconhecido no horizonte for confirmado como comprometido com o uso, ainda assim será preciso perguntar sobre a natureza da caminhada até lá chegar. Pode-se tomar o rumo básico de ensinar e aprender o sistema primeiro e ir ensaiando o uso paulatinamente ou pode-se viver a comunicação (mesmo que precariamente no início) e, nela, aprender a língua e, em alguns momentos, sobre ela. Esse segundo caminho é o que tenho tomado como o caminho da abordagem comunicativa e o primeiro o da abordagem sistêmica pela forma (gramatical).

É preciso reafirmar mil vezes que esses caminhos não são iguais variando apenas a paisagem - que possuem os mesmos elementos teóricos com ênfases distintas. Trata-se de qualidades distintas de ensinar e aprender línguas que precisamos reconhecer para escapar de confusões retardadoras do avanço das concepções e da prática de ensinar línguas.

Em seguida, quero reafirmar alguns traços distintivos essenciais que reconheço na grande abordagem comunicativa (o caminho da comunicação em direção ao horizonte de uso adquirido da nova língua). A primeira armadilha será evitada não se tomando que tudo é comunicativo no processo de aprendizagem, com isso implicando que nada é de fato e a rigor comunicativo.

No quadro que apresento a seguir (Quadro 1), separei os sentidos periféricos ou até mesmo errôneos do que seja "abordagem comunicativa" para as pessoas não-leigas, dos sentidos centrais que constituem a filosofia comunicativa. Estes dados foram preliminarmente levantados a partir de entrevistas com professores e exame de obras correntes de referência teórica.

\section{Quadro 1. Traços distintivos do paradigma comunicativo}

\section{Sentidos periféricos ou errôneos}

- Fazer uso da mídia

- Entender toda ação lingüística como comunicativa

- Tomar comunicação como de transmissão de sinais elétricos envolvendo tráfego de informação

- Referir-se ao movimento norte-americano de ensino de escrita a calouros baseado em habilidades e estratégias

- Indicação de foco na oralidade

- Equacionar ser comunicativo com possuir personalidade agradável, tom simpático, aberto, fluente e desinibido

- Abolir a gramática

- Fazer "joguinhos" e "dinâmicas" 
- Interagir (pura e simplesmente)

- Dialogar ou monologar criticamente na LI

\section{Sentidos centrais}

- Anti-anterioridade (anticentralismo) da gramática ou estrutura frástica no processo de ensino aprendizagem de línguas

- Foco em recortes de atividades desejadas produzidos na própria línguaalvo (Ex. Ouvir palestra e anotar, receber (ler) mensagem e respondê-la, iniciar conversação, etc)

- Primazia da construção de sentidos na LE num ambiente de compreensibilidade e ausência de pressāo emocional

- Processo complexo de ensinar e aprender línguas no qual a dimensão lingüística da forma não é a mais importante, mas subsidiária da dimensão social, cultural e eventualmente política

- Aprender comunicação na comunicação, mesmo que, no início, com andaimes facilitadores

- Deslocar a idéia de aprender língua pela língua para aprender outras coisas na língua-alvo e, nesse ambiente, aprender a língua

- Uso de nomenclatura não-gramaticalista, isto é, de terminologia específica como função, expoente de formulação, recorte comunicativo, papel social, tema, tópico, etc

- Observação dos interesses e eventuais necessidades e fantasias dos participantes para compor objetivos do curso

A realização desses traços do cerne comunicativo (acompanhados ou não de traços periféricos) num ensino alternativo caracterizado pela comunicação enquanto se aprende a nova língua não é, por certo, tarefa fácil de ser realizada na prática. A prática do ensino comunicativo não tem sido generalizada nos contextos nacionais e nem farta nos resultados de uma aprendizagem eficaz. Os resultados de pesquisa aplicada sobre questões do ensino comunicativo não têm sido suficientes para compor um quadro teórico sólido que respalde a prática renovadora. Isso pelos motivos que passo a expor:

- há tradição de aprender já arraigada entre professores e alunos, geralmente num híbrido de métodos da abordagem gramatical sedimentados por estrato social, por região, etc, e uma tradição tende a se defender de inovações que possam ameaçar o confortável equilíbrio de uma situação de aprendizagem ou ensino;

- idéias com força tomadas de fora da Linguística Aplicada/Ensino de Línguas que se candidatam a alavancar "mudanças" metodológicas 
de amplo alcance, quase sempre além do que podem oferecer essas idéias à grande operação do ensino de línguas na prática. (Acompanha uma postura aplicadora e muitas vezes salvadora que os inocentes não podiam ver: por exemplo, alguns criticalistas fundamentalistas escorados na $\mathrm{AD}$ de linha francesa ou criticalistas-transformadores na perspectiva de Freire);

- faltam condições externas cruciais para sustentar iniciativas de mudanças - é o caso flagrante da escarcidade ou mesmo ausência no mercado de materiais didáticos verdadeiramente alternativos (existem, é claro, muitos falsos comunicativos ou apenas comunicativizados para vender), mas também currículos conservadores, exames tradicionais, materiais-fonte como gramáticas pedagógicas, livros sobre concepções da comunicação, livros sobre o ensino comunicativo ou com outros nomes mas focados no sentido e na interação propositada;

- as bases teóricas do ensino comunicativo não estão disponíveis em formatos ou modelos portáteis que auxiliem o professor comum a compreender o que seja ensinar e aprender comunicativamente;

- o ensino comunicativo não está disponível ou é uma falsa opção para os professores de uma língua estrangeira que não apresentam um desempenho comunicativo nessa língua-alvo;

- o denominar (-se) comunicativo/a por uma faceta errônea, superficial e/ou fragmentada que banaliza os sentido mais centrais da abordagem comunicativa levando as críticas de espantalhos comunicativos criados para serem destruídos em argumentação "vanguardista" ou "ingênua";

- falta de compreensão rigorosa do que é abordagem. (Daí proliferarem as "abordagens" nos textos dos autores: abordagem oral, natural, humanista, crítica, socio-interacional).

\section{Observações finais}

Dado esse quadro do ensino de línguas no Brasil desde 1978, quando um evento acadêmico reuniu especialistas em torno do ensino comunicativo pela primeira vez no país, mais do que "e agora?" nós deveríamos estar indagando "por que chegamos só até aqui?", ou "até onde queremos chegar?" e "como chegaremos lá?". As respostas a essas questões todas apontam para uma análise histórica do que vimos realizando no país e para o exame atento dos pressuposto teóricos e as questões da 
prática comunicativa como alternativas à centralidade do sistema lingüístico no ensino de línguas. Quanto à questão dos métodos com os quais alcançar as metas, parte da resposta é mais pesquisa, mais publicações e mais autonomia no agendamento das perguntas da nossa época. A outra parte da resposta reside nos processo de formação de professores provavelmente através da auto-reflexão ou reflexão auto-sustentada em ações teoricamente bem informadas. O paradigma comunicativo está longe de ter exaurido seu grande potencial de recursos para renovar o ensino de línguas. Os esforços de pesquisa e implementação deverão nos ocupar bem mais além do ano de 2001.

Vivemos numa época em que muitos professores de línguas enfrentam questões ainda anteriores à da abordagem e metodologia. É o caso da urgente demanda por uma competência lingüístico-comunicativa que força uma prática calcada no estudo de pontos gramaticais para serem "passados" aos alunos já pouco convencidos de que obterão resultados palpáveis que justifiquem seu investimento no aprendizado. Nesse cenário incerto criticado fortemente por agentes especialistas não surpreende que muitos sonhem ser comunicativos e alguns poucos eleitos em ser críticos e já distanciados da abordagem comunicativa. A vanguarda do criticalismo deve radicalizar perigosamente a distância já apreciável entre o dizer (o que parece certo ou desejável) e o fazer (o que e como se ensina de fato). Entre muitos desafios é preciso ajudar os professores a compreender a qualidade do seu ensino pela (auto) observação.

É hora de esclarecer, reforçar, descartar ou reafirmar pressupostos na construção de uma experiência que pode fazer a diferença num país onde o corpo profissional de ensino de línguas está praguejado com limitações extrínsecas endêmicas e confusões teóricas sérias mas ao mesmo tempo tão esperançosamente ocupado com a sua (re)construção.

\section{Referências Bibliográficas}

ALMEIDA FILHO, J. C. P. Specifying the Notional-Functional Component for English in a Brazilian First-year University Course. 1977. Dissertação (Mestrado) - Universidade de Manchester, Inglaterra.

Dimensões Comunicativas no Ensino de Língua. Campinas:

Pontes Editores. 1993. 
(Org.). Parâmetros Atuais no Ensino de Português Lingua Estrangeira. Campinas: Pontes Editores. 1997.

Campinas: Pontes Editores. 1999.

(Org.). O Professor de Língua Estrangeira em Formação.

BARÇANTE ALVARENGA, M. Configuração de competências de um professor de língua estrangeira (inglês): implicações para a formação em serviço. 1999. Tese (Doutorado em Lingüística Aplicada), Instituto de Estudos da Linguagem, UNICAMP, Campinas.

BRASIL. Ministério da Educação. Parâmetros Curriculares Nacionais. Língua Estrangeira/Terceiro e Quarto ciclos da escola fundamental, 1998.

KUHN, S. The Structure of Scientific Revolutions. London: Falmers Press, 1970.

MARKOVA, E. Paradigms, Thought and Language. London: John Wiley \& Sons, 1982.

NEWMARK, $P$. On the necessity and sufficiency of grammar in language learning. TESOL Quarterly, v. 14, n. 2, 1966.

LEECH, G.; SVARTVIK, J. A Communicative Grammar of English. London: Longman. 1975.

WIDDOWSON, H. D. Teaching Language as Communication. Oxford: OUP, 1978.

O Ensino de Línguas para a Comunicação. Tradução de José Carlos Paes de Almeida Filho. Campinas: Pontes Editores. 1991. Título original: The Teaching of Language as Communication.

Explorations in Applied Linguistics. Oxford: OUP. 1979. 